\title{
MAROSA DI GIORGIO Y LA AFIRMACIÓN DE LA VIDA (1932-2004)
}

MAROSA DI GIORGIO AND LIFE AFIRMATION (1932-2004)

Graciela Rubio

Universidad de Playa Ancha, Valparaíso, Chile

\section{Resumen:}

Marosa Di Giorgio fue una escritora uruguaya que destacó tanto en poesía como en prosa. En su obra aparecen constantes alusiones a la naturaleza y abre un mundo que afirma la vida para conectar directamente con el ser y conocer sus propias emociones y vivencias.

Palabras clave:

Marosa Di Giorgio, Ariadna, vida.

\section{Abstract:}

Marosa Di Giorgio was an Uruguayan writer who stood out in poetry as well as in narrative. In her work there are so many references to nature and open a world which affirm life in order to connect with the being directly and know her own feelings and experiences.

\section{KeYwORDS:}

Marosa Di Giorgio, Ariadne, life. 
Su obra ha sido calificada como acción de audacia imaginativa, en la que el lenguaje configura mundos únicos. Marosa Di Giorgio es una de las grandes letras de Uruguay que ha logrado con maestría plasmar en el verso el devenir de la existencia.

Estaba parada en medio de la luz de la luna. A lo lejos, seres increíbles: Mario, los unicornios, los lobizones, la paloma de la paz, la liebre de marzo.

Deleuze nos afirma que Ariadna es el Anima, ella se encuentra en medio de dos mundos; la mistificación humanista y racional representada por Teseo y, aquella que deviene como "afirmación pura y múltiple"desde el encuentro con Dionisos -Toro. Aquella que históricamente se ha negado a sí misma desde la "unicidad" del sujeto racional moderno. En una encrucijada, Ariadna se presenta como una mediadora que "sin saber" abre paso al dialogo entre estos dos mundos. "Eternamente afirmación del ser; yo soy eternamente tu afirmación". Así dialoga una vez unida a Dionisos ${ }^{2}$. Esta referencia nos parece pertinente para aproximarnos a la obra de Marosa, toda vez que su voz lírica está dispuesta a ser la afirmación de otro.

La voz de Marosa abre el mundo que afirma la vida y dialoga con la razón desde el deseo. A diferencia de Ariadna, Marosa abre voluntariamente este mundo (no lo construye, pues existe) y se transforma en la mediadora que nos "lanza" el hilo de la memoria /deseo para transitar por el laberinto/bosque de su infancia y juventud. La memoria es la red que configura el relato en el cual, seres "corpóreos" y mágicos transitan su propia temporalidad para abrirse a la transformación permanente y a la ruptura del espacio tiempo, cada vez que la intensidad de la vivencia demande el encuentro entre estos dos mundos.

"A veces, en la madrugada, llovía dulcemente, y parecía que un enjambre caía del cielo, que los muertos volvían a la vida, que todo estaba bien.

1 Deleuze Gilles. EL Misterio de Ariadna. Nietzcheana.com .ar/deleuze.htm. Publicado en Magazine Litteraire,n298,1992. Traducido para cuadernos de Filosofía por E. Gutierrez. Deleuze nos afirma que Dionisos-Toro, esa unión es la afirmación pura, aquella existencia que no "carga," el conocimiento y la moralidad como lo hace la racionalidad moderna. "Laberinto del conocimiento y de la moral". Dionisos representa la existencia como devenir en estado puro y Ariadna su "eterna afirmación" (El Sí). Ariadna viene a ser en su transmutación, el alma desdoblada, "El sí que responde al si". Dionisos teme estar sólo, porque teme al eterno retorno de las fuerzas "reactivas" (Teseo) que niegan la vida, pero al encontrar a Ariadna se percata de que el eterno retorno es selectivo y que "No hay eterno retorno sin transmutación". Nosotros agregamos no hay recuerdo (retorno) que no sea selectivo y sin transmutación. Marosa, enuncia la permanente posibilidad de recordar como otro. Antes de encontrarse con Dionisos, "...Ariadna enamorada habría acompañado al héroe e iluminado el recorrido con el fulgor dorado de la corona que llevaba en la cabeza o con una guirnalda luminosa. Los antiguos vieron en ello un añadido a la ignominia de aquella traiciónVer texto laberinto. Santarcangeli. Paolo. (2002) El Libro de los Laberintos. Ediciones

2 Deleuze, op cit. Yo soy tu afirmación. Introduce el yo como otro. La reflexión de Deleuze nos invita a comprender la identidad como otro, aproximación divergente de la racionalidad moderna, centrada en el sujeto. Deleuze pretende continuar la crítica a la modernidad racionalista iniciada por Nietzsche para "afirmar la vida". 
Yo me asomaba a la ventana, y a la media luz, ya todas las hojas eran granates y amarillas, livianas y fragantes; como uvas o amapolas.

Y entre los grandes árboles, los monjes en sus casetas, pequeñas, entre las ramas. El nuestro salía a mirar la lluvia, los relámpagos, anotar en su Cuaderno del Tiempo, el monje de astas larguísimas y sedosa pelambre. ${ }^{3}$

\section{MUNDO DIALÓGICO}

Este mundo dialógico se caracteriza por la perpetua transmutación de sus seres de lo que se infiere un permanente estado de liberación del cuerpo, el espacio, el tiempo y la razón así como de la infinita creación."Livianismimas mariposas estaban adosadas al tronco. Parecían una decoración; eran mi alma, dividida en varias figuras (que no existía), tornasolado; los ojos de algunas, redondos, grandes, negros, planos. Los de las otras, hechos con montículos de brillantes, sobresalían mucho." ${ }^{4}$ La voz desdoblada en y a través de los eventos que se suceden intempestiva y abruptamente, sin dejar de reconocerse a sí misma, teje el dialogo posible que configura mundos nuevos pudiendo la existencia y la no existencia devenir en un mismo presente ya.

Cada episodio recordado es vivido como un presente que se manifiesta en estado de realización, sin orden, sorpresivo e inquietante. La escritura, sus lenguajes y expresiones estéticas se deslizan en un mundo en que el tiempo se desplaza a través del lenguaje como posibilidad emergente, como acto puro, es decir," todos los acontecimientos". ${ }^{5}$ El fluir permanente del mundo dialógico de Marosa configura una particular temporalización de los significantes, en que las formas conjugadas del pasado presente y futuro aparecen trastocadas por la propia temporalidad, configurando diversas presencias en un mismo instante, o volviendo el pasado un presente deviniendo sorpresivo, determinando así, una existencia particular de sujetos y verbos en el espacio. Desde este redimensionamiento de la realidad, la poesía cruza los umbrales de la racionalidad moderna para situarse en el "instante" en que todo sucede y todo puede suceder. En el momento en que relato y deseo se vuelven actualidad en la pura palabra. De allí deriva la estructura de su poética que puede ser leída como totalidad en el fragmento, y como totalidad en el poema relato, pues Marosa logra incluir el todo en la parte y la parte en el todo.

Es junio y de tarde en los tiempos druídicos, el techo empieza a irse, a volar como una nube. El zapallo se entreabre, da su olor a rosa, el extraño aroma a clavel de los zapallos. Mamá está cerca del fuego, labra un pastel, grande. Yo voy de hache para

3 Di Giorgio M. (2004) La Flor de lis.(poemas a Mario). El cuenco de Plata/latinoamericana.p7

$4 \quad$ Digiorgio M. op cit $\mathrm{p} 12$

5 Deleuze, Gilles (1994) La lógica del sentido. Paidos Barcelona. p25-28 
allá. El pastel parece un hombre, es como un fantasma, tiene ojos azules y cabello largo. Me acerco al aparador, enumero las tacitas una a una, todas son livianísimas como cáscaras de huevo; la dulcera es rosada como una rosa. . Mama me llama, voy hacia a ella; el pastel gime un poco, conversa con mama. Afuera va a caer la noche; las plantas se quedan inmóviles, hamacan. ${ }^{6}$

\title{
II EL BOSQUE/LABERINTO
}

El bosque, jardín secreto de los recuerdos en Marosa, es el fondo memorial en el cual se entreteje el pasado, aquel que permite reunir en un mismo y múltiples sujetos, todos los tiempos y todas las experiencias a la vez. El bosque se configura como un no lugar disponible, para ser transitado sin temor a ser cruzado a diferencia del mito del laberinto, hasta para recordar en él lo que no sucedió. "Te apoderaste de todo, hasta de los recuerdos de cuando no te conocía"7. Los versos del bosque están llenos de "erotismo afirmativo", de voluntad erótica que se manifiesta en niñas-mujeres las que nutridas desde la vivencia del deseo, actúan prescindiendo de toda moral para, afirmar toda posibilidad.

\begin{abstract}
"Era de noche cuando apareció el Animal, hecho sólo con Hibiscos. Estaba absolutamente quieto y mudo. Y todo hecho con hibiscos. Hibiscos rojos, morados, blancos, lilas, color oscuro. Desde lejanísimos cielos caía una llovizna finísima, celeste, que no mojaba, iluminaba. Yo mire al Animal hecho sólo con Hibiscos y no sabía como nombrarlo, llamarlo. Y creí que no debía hablar pues él estaba mudo, inmóvil mI voz rompería una ley. Le observé las flores que lo conformaban, en la cabeza, el lomo, los pies, la cola, todas sus flores.....Me tendí a su lado y empecé a vibrar....Entonces, me levanté y arranqué unas de las flores mas intimas del Animal hecho solo con Hibiscos, me volví a tender, puse las flores adentro de mi vulva, las empuje mas adentro..."
\end{abstract}

Este mundo libre de moral y razón, se presenta desde las ansias 'puras, como afirmación de todos los eventos posibles, y como un descubrimiento permanente. Un gran eje articulador, el deseo/vida es el que "ordena" a disposición del momento, el espacio.

“Es la tarde del verano; estoy en el jardín, en los higueras, ¿por qué ando por ahí?.

Tengo puesto el delantal

casero, llevo canastillas y tijeras. Corto, higos, rosas.

Pero si no me moví del lecho. Igual devoro un higo, una flor.

De lejos custodio a Mario; allá lejos, ojos verdes, fuego de sol. De luna, fuego.

Sigo a Mario, soy una armiña, un blanco animal. Sedoso el pelo, el paso. Ando con

cautela desafiante: llevo esto por el lomo, entre las patas, camelia ágata.

Soy un armiño, una rosita.

6 La guerra de los huertos. Papeles salvajes (1989) Adriana Hidalgo editora Vol. 1 p150

$7 \quad$ Di Giorgio M op cit p10

8 Di Giorgio.M op cit p30 
Con esas máscaras sigo a Mario. Con esta máscara y a cara limpia..

¿Qué paso?... ¿qué...? Acaso, nada.

Los ejércitos de Dios cruzaban la tormenta; impávidos brillaban. ${ }^{9}$

De allí que la erótica en Marosa se vuelva carne, vida y muerte a la vez, añoranza y desfallecimiento. "El pensamiento del león se hizo espeso. Como una mancha de aceite grueso. Luego la arrastró al lugar más hondo de la cueva. Le lamió la cara. Ella se sonrió. Le hizo los mimos íntimos muy adentro. La médula de ella dijo ¡ay!... ¡aaaay!.. Cantó cual mandolina, se la oyó en el aire. Ahí le comió la cabeza. De golpe y a pedacitos. Luego, le durmió un rato sobre el corazón."10

Marosa nos conduce sin mediar al fondo de la experiencia deseosa procurando actualizarla en la palabra/instante, ajena al conocimiento y la moral, en cualquier contexto, y en la conciencia individual. ${ }^{11}$ Las acciones en este mundo laberíntico se vuelven devenires en proceso de transformación en la voz lírica, a la vez que totalidades sustantivadas en las que la atención se fija guiada por la intención de Marosa de enunciar el desconcierto que provoca la vivencia del recuerdo desde el tiempo.

"Yo en vez de cabello tenia víboras. Salían de las sienes de la frente, e iban mucho más debajo de los hombros. Y eran hermosas, la base blanca y, el largo lomo, verde con pintas punzó o plateadas. Abrían la boquita escintilante y hacían Sh Sh...Era intraducible lo que decían las víboras.

Todos se aterraban un poco y las maestras, sin que yo tuviese culpa alguna me ponían en penitencia detrás del pizarrón, más luego me volvían al banco con mi melena brillante y silbante.

Algunas noches, acostada yo tenía miedo aunque no lo dijese. Sola con ellas en la cama. Pero no podía sacarme el cabello (ellas).

Creo que en ocasiones una creció y se introdujo en el pezón otra en el otro. Me extraían la leche. Y fueron mucho más lejos.

Yo quedé inmóvil. ¿Qué será eso que inventaban las víboras? ¿O estaría yo soñando?

................Cuando conocí a Mario una noche de agosto, ¿qué le iba a decir?.

Yo soy la mujer de las víboras y las víboras de la niña?

$9 \quad$ Di Giorgio op cit p29

10 Fragmento del Camino de las Pedrerías. Obsérvese la relación entre los dos mundos y la sorpresa "imposible de nombrar por aquella que fue devorada" para luego transitar al gesto amoroso del reposo de quien (el animal) se cobija en el que ama.

11 Había desde el árbol un sonido. Ella parecía estar ajena a todo. Pero seguía viniendo un leve rumor de pericos y de lirios. ¿No escucha nada? dijo, El. ¿Es todo de flor, señora? Acabo de comerle la cosita. ¿Le gustó? Veo que tiene muchas. Vaciló, subió a mirarle los senos había olvidado, de eso que nunca se olvidaba. Grosos bellos. Y habían quedado fuera. Con ellos no copuló. Le miró la cara que se mecía un poco. Estaba dormida. Tenía un ojo cerrado. El otro ojo confuso abierto, le decía: Prosiga señor, no siga. Señor, prosiga. El misal del árbol p25/26 Misales (2001) LOM op cit este corto relato ofrece una multiplicidad de identidades-voces en la que los personajes se desdoblan en sus roles eróticos hasta el punto de perder la identidad configurada al inicio del dialogo amoroso. Es interesante destacar el desdoblamiento de la voz y el rol que asume desde la erótica como un carácter trasgresor de la identidad, de la forma y obviamente de la moral. El ser "se despega" del árbol en su afán de copular y encuentra a la señora 
No se podía entender. ${ }^{12}$

Al mismo tiempo, la voz que transita por el tiempo se deja llevar por los eventos narrando en el propio proceso, vivenciando el instante de la transformación intempestiva y perpetua, a la vez que es capaz de detenerse en un pulso siendo una con el instante, para luego decidir desde allí su orden del relato.

(...)Ella de prestó. Arriba de ellos bramaba el maizal, una música como un funeral. Parecía que estaban en una iglesia. Que la sacrificaban por primera vez.

El se atrevía a más. El parecía un santito derribado en el suelo.

Bramaron mucho. El la miraba a través del maíz si no venía el patrón. Ella tendía una mano y tocaba una sandía, cuando no sabía que hacer transida hasta el fin. El se separó un instante, pensó en irse, disparar, pero volvió a la labor. Señora Azucena.

Ella dijo-Bien, señor, no puedo más.

Y temblaban los ojos opalinos, los senos que parecía iban a dar leche como los higos. Váyase, ahora, señor.

Espero la otra parte. Mándela, de lejos.

El quedó absorto. Pensó se habría enloquecido.

El se asustó, se puso detrás de una planta, alta de maíz con mazorcas, que parecía un militar que lo prendía, que lo iba a encarcelar, que ya lo llevaba preso. Ahí entró la mariposa, volvía del infinito. Plegó sus alas, se aplicó, temblaba en el delito. ${ }^{13}$

\section{RECORDAR DEVINIENDO OTRO}

Marosa evidencia que cada vez que recuerda lo hace como otro. Efectivamente, su voz se desplaza libremente a través de espacios, estados, deseos, pensamientos, sólo palabras, liberando al significante de normas que indiquen como y desde quien recordar. Su voz dispuesta a abrirse a lo otro fluye como si se estrellara gustosa a sí misma sobre los sujetos (animales, Ángeles, plantas, hombres y, mujeres, objetos, todos los seres) para develar la intensidad del un hecho puro manifiesto.

"Mi alma es una gasa inmensa, livianísima; está por todo; es una mariposa espesa, cuyas firmes piernas de hilo asen lo que fue o es de mí. Y para siempre. Tiene apretados los vestidos antiguos, las trenzas, las caravanas en forma de trébol; y lo de ahora, dijes, figuritas de vidrio o porcelana, que me rodean. No quiebra nada. Mi alma va a la chacra y trae cosas, visita la bodega, el altar, la cocina, la casa, y trae cosas, tinajas, pomelos, zapallos y demás, y los vende por el camino en los días de necesidad, y me trae los resultados.

¡Cómo? Ella, tan leve y tan magna! ¿Cómo?, si ya voló hace tiempo, la chacra, si no hay nadie, nada sólo un vacío campo con matas de frambuesas salvajes.

Pero ella va y me trae cosas.

En esta noche de asiduos relámpagos y tormentas ocupa un pequeño sitio, parece

12 Di Giorgio M. Op cit $\mathrm{p} 39$

13 Misal final con alitas. En Misales(2001)Editorial LOM Santiago.p55 
un tul arrollado. Veo a mi alma. En la onda oscuridad están sus ojos brillantes, fijos, celestes, de muñeca. ${ }^{14}$

Puede también abrir relatos aparentemente biográficos, como si nos contara lo que sucedió para luego en el contexto de la misma narración, como si la voz estuviera observando a la vez que contando, incorporar los eventos emergentes a su propio ser, esto es ser la afirmación de la existencia plena; todas las existencias posibles, incluidas las ausentes de claridad:

“Así que me casé con Mario, pero él está en la casa; es de noche y yo en esta rama, y soy una mariposa, blanca, con alas grandes y vaporosas, creo que cuatro, de diversa extensión, la cara plateada, las manos de hilo negro.

Mamá, como siempre, me supervisa desde las violetas.(¿Pero como voy a estar yo cazada?!).De seguro, mamá prosigue ahí en el violetario.

Yo, entornes, ¿no cuido la mesa, la cama, la silla, no prendo una lámpara?.

En el cielo cruza un pájaro y hace rag rag.

Cae una estrella y parece que va a haber un incendio.

Pero todo queda en paz. ${ }^{15}$

Marosa se ha lanzado voluntariamente a dialogar con su propia memoria y las presencias y ausencias que son posibles de abordar en el recuerdo. Dicho dialogo/ recuerdo manifiesta lo que hemos llamado la afirmación de la vida que libera a la palabra para hacerla transitar por un laberinto inquietante, y dramático (así ella define su poesía), vital y alegre, que se abre a subvertir la relación previsible y conocida entre significante y significado.

Si al recordar necesitamos transitar a través de otros, pues cada vez que recordamos lo hacemos con otros (aludimos a ellos), Marosa, apoderándose de esta consideración fenomenológica eleva la experiencia del recuerdo a una liberación del tiempo y espacio que remite a un sujeto solitario (el racional moderno) para crear un mundo como otro desde un re-conocimiento de la experiencia vivida. Tal como Ariadna lo habría manifestado al "unirse" al Dios -Toro.

Yendo por aquel campo, aparecían, de pronto, esas extrañas

cosas. Las llamaban por allí, virtudes o espíritus. Pero, en verdad eran la producción de seres tristes, casi inmóviles, que nunca se salían de su lugar.

Estancias al parecer, del otro mundo, y casi eternas, porque el viento y la lluvia las lavaban y abrillantaban, cada vez más. Era de ver aquellas nieves, aquellas cremas, aquellos hongos purísimos... Esos rocíos, esos huevos, esos espejos.

Escultura, o pintura, o escritura, nunca vista, pero, fácilmente descifrable.

14 Di Giorgio. M op cit p23-24.

15 Di Giorgio. Op cit p78 
Al entreleerla, venía todo el ayer, y se hacía evidente el porveir. ${ }^{16}$

\section{BIBLIOGRAFÍA}

Deleuze, G. (1984). La imagen-movimiento. Barcelona: Paidós.

Deleuze, G., \& Lapoujade, D. (2003). Gilles Deleuze. adpf.

Deleuze, Gilles (1994) La lógica del sentido. Paidos Barcelona. p25-28

Di Giorgio M. (2001). En Misales. Editorial LOM: Santiago

Di Giorgio, M. (1979) Clavel y tenebrario. http://amediavoz.com/digiorgio.htm

Di Giorgio, M. (2004). La flor de lis. El cuenco de plata.

Di Giorgio, M., \& Helder, D. G. (2000). Los papeles salvajes. Adriana Hidalgo.

Echavarren, R. (1992). Marosa di Giorgio, última poeta del Uruguay. Revista Iberoamericana, 58(160), 1103-1115.

Echavarren, R. (2004). Marosa di Giorgio. Guaraguao, 8(19), 89.

La guerra de los huertos. Papeles salvajes (1989)Adriana Hidalgo editora Vol. 1 p150

Olivera-Williams, M. R. (2005). La imaginación salvaje: Marosa di Giorgio. Revista Iberoamericana, 71(211), 403-416.

16 Clavel y tenebrario" $1979 \mathrm{http} / / /$ amediavoz.com/digiorgio.htm 